\title{
pBLA8, from Brevibacterium linens, belongs to a Gram-positive subfamily of ColE2-related plasmids
}

\author{
Véronique Leret, Annie Trautwetter, Alain Rincé and Carlos Blanco
}

Membranes et

Osmorégulation, UPRES-A

6026, Université Rennes I,

Avenue du Général

Leclerc, 35042 Rennes

Cedex, France

\author{
Author for correspondence: Carlos Blanco. Tel: +332992861 40. Fax: +33299286140. \\ e-mail : Carlos.Blanco@univ-rennes1.fr
}

\begin{abstract}
A 3.1 kb DNA fragment from pBLA8, a Brevibacterium linens cryptic plasmid, containing all the information required for autonomous replication was cloned and sequenced. Using deletion analysis, the fragment essential and sufficient for autonomous replication was delimited to $1.5 \mathrm{~kb}$. This fragment is characterized by the presence of an ori site located upstream of an operon encoding two proteins, RepA and RepB, both essential for replication. Based on structural similarities and a strong conservation of ori, RepA and RepB, PBLA8 was assigned to a new subfamily of the ColE2 plasmid family. This subfamily is distinguished by the requirement for two Rep proteins and the location of an ori site upstream of the repAB operon. RepA is thought to encode primase activity, whereas RepB could be a DNA-binding protein. An Escherichia coli-B. linens shuttle vector, derived from pBLA8, was constructed. Its host spectrum was extended to Arthrobacter species.
\end{abstract}

Keywords: Brevibacterium linens, plasmid replication, ColE2 related plasmids, shuttle vector

\section{INTRODUCTION}

The genus Brevibacterium includes irregular nonsporing, Gram-positive, strictly aerobic rods, and belongs to the same group of coryneform bacteria as the genera Corynebacterium, Arthrobacter, Cellulomonas, Curtobacterium and Microbacterium. Within this group, Corynebacterium is distinct from the others with regard to its cell wall and lipid composition that make it closely related to Mycobacterium, Nocardia and Rhodococcus (Collins \& Cummins, 1986).

Among coryneform bacteria, the Corynebacterium plasmids are by far the best known because of the industrial potential of a number of species, which has motivated studies of their genetics. pBL1, isolated from Corynebacterium glutamicum (Santamaria et al., 1984) has given rise to numerous cloning vectors (Martin et al., 1987). Subsequently, other C. glutamicum plasmids, including pSR1 (Archer \& Sinskey, 1993), pCG100 (Trautwetter \& Blanco, 1991), pGA1 (Nesvera et al., 1997) and Corynebacterium diphtheriae pNG2

\section{Abbreviation: $\mathrm{HTH}$, helix-turn-helix.}

The GenBank/EMBL accession number for the PBLA8 minimal replication region reported in this paper is $Y 11902$.
(Serwold-Davis et al., 1990) have been identified. After being widely used to develop genetic tools, pBL1, pSR1, pNG2 and pGA1 were all shown to replicate via a rolling-circle mechanism (Archer \& Sinskey, 1993; Fernandez-Gonzalez et al., 1994; Nesvera et al., 1997; Zhang et al., 1994) which might result in a serious instability behaviour, as has already been reported for pBL1 derivatives (Fernandez-Gonzalez et al., 1994). The replication of the $C$. glutamicum pBL1 derivatives in Brevibacterium linens was reported by Sandoval et al. (1985) but this result could not be reproduced either in our laboratory or by Ankri et al. (1996). Similarly, we were unable to introduce pCG100 derivatives into $B$. linens.

To date, only three $B$. linens plasmids have been described: pBL100 (Sandoval et al., 1985), a closely related plasmid pBL33 (Bigey et al., 1995; Kato et al., 1989) and pRBL1 (Ankri et al., 1996). Nevertheless, little is known concerning their replication, except that pRBL1 is thought to replicate via a theta mechanism (Ankri et al., 1996).

In this report we describe the identification and characterization of the region involved in the replication of the plasmid pBLA8, isolated from $B$. linens. We provide evidence that it belongs to a new subfamily of ColE2- 
related plasmids and describe a cloning shuttle vector derived from pBLA8 that is replicative in Escherichia coli, B. linens and Arthrobacter.

\section{METHODS}

Bacterial strains and plasmids. The $B$. linens strains screened for the presence of small plasmids included $26 \mathrm{CNRZ}$ strains (CNRZ201-224 and 937-940) and ATCC 9172, 9174, 9175 and 19391. The strains used for pBLA8 replicative host spectrum studies were C. glutamicum ATCC 6872, 13058, $13287,14020,21488,21649,21792,21086$ and 21491, and the restriction-defective strains RM3 (Schafer et al., 1990) and BL15 (Bonnassie et al., 1990), Arthrobacter sp. SI55, Arthrobacter globiformis CCM1650, Arthrobacter simplex CCM1652, Arthrobacter variabilis CCM1565, Arthrobacter ramosus (Trautwetter \& Blanco, 1988) and 'Arthrobacter aureus' C70 (Le Marrec et al., 1994).

Recombinant plasmids were selected in E. coli NM522 [supE thi $\Delta$ (lac-proAB) $\Delta($ hsdMS-mcrB $) 5 \quad \mathrm{~F}^{\prime} \quad\left[\right.$ proAB lacl $^{\mathrm{q}}$ $\Delta$ lacZM15] (Mead et al., 1985). The E. coli plasmids were: pBS8 (Spratt et al., 1986), pJRD16905 (Trautwetter \& Blanco, 1991), pSU20 (Bartolomé et al., 1991), pBluescriptII SK+ (Stratagene) and pBK, a kanamycin-resistant homologue of pBluescriptII SK + (Le Marrec et al., 1996). These plasmids contain kanamycin- or chloramphenicol-resistance determinants, which can be selected in $E$. coli and corynebacteria but do not replicate in the latter. p21530, derived from pBL1 (Bardonnet \& Blanco, 1991), and p25450, derived from pCG100 (Trautwetter \& Blanco, 1991), were used to investigate the compatibility of pBLA8 derivatives with other replicons in ' $A$. aureus' $\mathrm{C} 70$.

Growth conditions. Strains were grown on LB medium (Miller, 1972) at $30^{\circ} \mathrm{C}$ for coryneform strains and $37^{\circ} \mathrm{C}$ for $E$. coli. Kanamycin, ampicillin and chloramphenicol were used at $50 \mu \mathrm{g} \mathrm{ml}^{-1}$ and tetracycline at $10 \mu \mathrm{g} \mathrm{ml}^{-1}$ in E. coli cultures. For coryneform strains, kanamycin was used at $90 \mu \mathrm{g} \mathrm{m}^{-1}$ and chloramphenicol at $3 \mu \mathrm{g} \mathrm{ml}^{-1}$.

DNA manipulation. Extraction of E. coli plasmid DNA, and of plasmid and chromosomal DNAs from coryneform bacteria were carried out as previously described (Le Marrec et al., 1994; Moreau et al., 1995; Sambrook et al., 1989; Trautwetter \& Blanco, 1991). The DNA sequences were determined by the dideoxy chain-termination method (Sanger et al., 1977) using the Sequenase version 2.0 DNA sequencing kit (United States Biochemical). Database searches were performed using FASTA (Pearson \& Lipman, 1988) and BLAST (Altschul et al., 1990) programs. Multiple sequence alignments were performed using CluStaL w (Thompson et al., 1994).

Transformation procedures. E. coli cells were transformed by the method of Mandel \& Higa (1970), Arthrobacter strains and C. glutamicum RM3 as described by Le Marrec et al. (1994), and C. glutamicum BL15 as reported by Bonnassie et al. (1990).

For transformation of $B$. linens, cells were grown to midexponential phase $\left(\mathrm{OD}_{570} 0.5\right)$ in $\mathrm{LB}$ medium supplemented with $10 \%(\mathrm{w} / \mathrm{v})$ sodium succinate and $2 \%(\mathrm{w} / \mathrm{v})$ glycine. Then $0.3 \mu \mathrm{g}$ penicillin $\mathrm{ml}^{-1}$ was added. When an $\mathrm{OD}_{570}$ of 1 was reached, cells were harvested, washed twice with 0.1 culture volume of cold $0.8 \mathrm{M}$ sucrose, resuspended in the same solution to obtain an $\mathrm{OD}_{570}$ of 60 and kept on ice. For electroporation, $0.2 \mathrm{ml}$ cells was mixed with plasmid DNA and immediately introduced into a pre-cooled $2 \mathrm{~mm}$ cuvette and pulsed with instrumental settings of $25 \mu \mathrm{F}, 2.5 \mathrm{kV}$ and
$400 \Omega$. The cell suspension was immediately diluted with $0.8 \mathrm{ml} \mathrm{LB}$ medium supplemented with $0.5 \mathrm{M}$ sucrose, incubated at $30^{\circ} \mathrm{C}$ for $90 \mathrm{~min}$ and plated on $\mathrm{LB}$ medium supplemented with $0.5 \mathrm{M}$ sucrose and the requisite antibiotic.

Isolation of a plasmid-cured derivative of B. linens ATCC 19391. A culture of a p18215 transformant of $B$. linens was grown overnight on LB medium supplemented with $50 \mu \mathrm{g}$ kanamycin $\mathrm{ml}^{-1}$ and $15 \mu \mathrm{g}$ acridine orange $\mathrm{ml}^{-1}$. Plasmid-free cells were identified as $\mathrm{Kan}^{\mathrm{s}}$ clones by replica plating.

Copy number and maintenance. Cells were grown to $\mathrm{OD}_{570} 1$ in LB medium containing the appropriate antibiotic. Then $40 \mu \mathrm{Ci}(1.48 \mathrm{MBq})\left[\right.$ methyl $\left.{ }^{3} \mathrm{H}\right]$ thymidine was added and culture was continued for $20 \mathrm{~min}$. Cells were harvested and washed twice with $0.5 \mathrm{ml} 10 \mathrm{mM}$ Tris $/ \mathrm{HCl}, \mathrm{pH}$. Total DNA was extracted as previously described, except that proteins were extracted once with phenol/chloroform/isoamyl alcohol $(25: 24: 1)$ and once with chloroform. An unlabelled aliquot of the plasmid of interest was added to each sample, and chromosomal and plasmid DNAs were then separated on a $0.8 \%$ agarose gel. After ethidium bromide staining, individual bands were cut out, dissolved in $\mathrm{NaI}$ at $50^{\circ} \mathrm{C}$ and prepared for scintillation counting. The radioactivity of each band was measured, and the plasmid copy number was estimated from the total plasmid and chromosomal radioactivity, taking into account plasmid and chromosomal molecular mass (Correia et al., 1994).

For determination of plasmid maintenance, plasmidharbouring strains grown under selective conditions were diluted in fresh medium without antibiotic and grown to late exponential phase. Subcultures were then performed in the same way, without antibiotic, for 80 generations. The antibiotic-resistance phenotype of the cells of the last culture was analysed on solid LB medium in the absence or presence of kanamycin or chloramphenicol. The percentage of antibiotic-resistant clones was determined and the presence of plasmid checked on selected isolates by DNA extraction.

Compatibility with PBL1 and pCG100. 'A. aureus' C70 harbouring $\mathrm{p} 4741\left(\mathrm{Cm}^{\mathrm{R}}\right)$ was electrotransformed with $\mathrm{p} 21530$ or $\mathrm{p} 25450, \mathrm{Km}^{\mathrm{R}}$ derivatives of $\mathrm{pBL} 1$ and $\mathrm{pCG} 100$, respectively. The resulting transformants were selected for the incoming plasmid and then analysed by replica plating on kanamycinand chloramphenicol-containing LB medium. The plasmid DNA content of selected colonies was analysed.

Construction of pA2209, an E. coli-B. linens shuttle vector. The bla gene of pBluescriptII SK + was deleted by Cfr $10 \mathrm{I}$ digestion, yielding p11915. The $3.85 \mathrm{~kb}$ EcoR I-Xhol fragment of p19373, containing the pBLA8 replicon and aphIII, was recovered. The ends were filled in with Klenow polymerase and the resulting fragment was inserted into the Dral site of p11915, yielding pA2209. This plasmid conserved lacZ $\alpha$ of pBluescript, facilitating the screening of recombinant plasmids in E. coli with ApaI, ClaI, DraI, HindIII, BamHI, NotI, SacII, SpeI, XbaI, EcoRI and the unique Xhol site located in the multiple-cloning site. Moreover, to keep the PstI site in the multiple-cloning site unique, the PstI site present in the pBLA8 sequence was destroyed by moderate S1 digestion.

\section{RESULTS AND DISCUSSION}

\section{Isolation and preliminary characterization of pBLA8}

To obtain a plasmid able to replicate in $B$. linens, we searched for plasmids in our $B$. linens strain collection. Plasmids are not common in B. linens and in fact only 


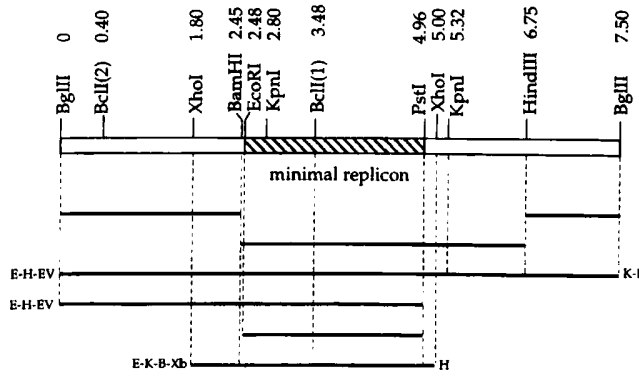

Plasmid

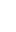

pBLA8

p18135 (pJRD16905/H-B) p18136 (pJRD16905/H-B) p18215 (pJRD16905/B) p19373 (pJRD16905/B-P) p18399 (pJRD16905/E-P) p4741 (pSU20/X)
Fig. 1. PBLA8 derivatives and their replicative properties. The upper line shows the linearized restriction map of PBLA8; only relevant sites are indicated (their positions are given in $\mathrm{kb}$ ). The minimal replicon is represented by a hatched box. Beneath are shown the cloned PBLA8 restriction fragments. Relevant vector restriction sites are indicated at the ends of the insert when needed to orient it within the vector, which is shown in parentheses, as are the restriction sites used for cloning. The ability $(+)$ or inability $(-)$ of the pBLA8 derivative to replicate in $B$. linens ATCC $19391 \mathrm{C}$ is indicated on the right. B, BamHI; E, EcoRl; EV, EcoRV; H, HindlII; K, Kpnl; P, Pstl; Xb, Xbal; X, Xhol.

Table 1. Features of ORFs encoded by the Xhol-Pstl region of pBLA8

\begin{tabular}{|c|c|c|c|c|c|}
\hline ORF & Frame & Start & Stop & $\begin{array}{c}\text { Shine-Dalgarno } \\
\text { motif }\end{array}$ & $\begin{array}{l}\text { Molecular } \\
\text { mass (Da) }\end{array}$ \\
\hline 1 & +2 & 17 (ATG) & 280 & AGGAG & 8988 \\
\hline 2 & +3 & 668 (ATG) & 985 & AGGGA & 11900 \\
\hline $3(\operatorname{RepA})$ & +2 & 1298 (ATG) & 2248 & GGACG & 35562 \\
\hline 4 (RepB) & +3 & 2244 (TGG) & 2468 & AGCGA & 8559 \\
\hline 5 & +2 & 2467 (ATG) & 2714 & AGGACG & 9227 \\
\hline 6 & +1 & 2713 (ATG) & 2988 & ATCCAGG & 9743 \\
\hline 7 & -1 & 516 (ATG) & Truncated & AGTGGAGGAG & Truncated \\
\hline
\end{tabular}

one plasmid was found, in ATCC 19391: it was named pBLA8. Its restriction map (Fig. 1) and size of $7.5 \mathrm{~kb}$, made it clearly different from $B$. linens pRBL1 (Ankri et al., 1996), but similar to pBL33 (Kato et al., 1989) and pBL100 (Sandoval et al., 1985). This latter differs from pBLA8 by the absence of a $0.55 \mathrm{~kb}$ Sall fragment only.

EcoRI-, HindIII-, PstI- and BglII-linearized pBLA8 were inserted into the corresponding compatible sites of pBS8 and pJRD16905. The recombinant plasmids were all replicative in $B$. linens ATCC 19391, suggesting that the restriction sites used are located away from the replication functions. In every case, the resident $\mathrm{pBLA} 8$ was absent from the plasmid content of the transformed $B$. linens cells, facilitating the isolation of a B. linens ATCC 19391 plasmid-free derivative, named ATCC 19391c, by acridine orange curing. Southern blotting experiments confirmed that ATCC 19391c actually contained no DNA sequence homologous to pBLA8 (data not shown). All the constructions that were replicative in ATCC 19391 were also replicative in ATCC 19391c, so the plasmids were perfectly autonomous.

\section{Electrotransformation of B. linens ATCC 19391}

The electrotransformation protocol used for $C$. glutamicum strains yielded very few transformants when used for B. linens ATCC 19391. Nevertheless, these early transformants provided a source of homologous DNA and allowed the optimization of the protocol. Several variables were investigated: (i) composition of the growth medium used before and following electroporation; (ii) composition of the cellresuspension media prior to electroporation and (iii) electrical settings. The efficiency of electrotransformation obtained with the optimized procedure (described in Methods) was $5 \times 10^{4}-1 \times 10^{5}$ transformants per $\mu \mathrm{g}$ homologous DNA, but only 10-50 transformants per $\mu \mathrm{g}$ heterologous DNA, which is prohibitive for direct cloning in $B$. linens. This protocol gave the same efficiency of transformation in the wild-type and the plasmid-cured derivative, and was used for all transformations described hereafter.

\section{Localization of the pBLA8 minimal replicon necessary for autonomous replication}

To define the minimal region of pBLA8 that is essential for its replication, various pBLA8 restriction fragments were cloned into the $E$. coli vectors pJRD16905 $\left(\mathrm{Km}^{\mathrm{R}}\right)$ or pSU20 $\left(\mathrm{Cm}^{\mathbf{R}}\right)$ and tested for their ability to promote plasmid replication in $B$. linens ATCC 19391c. p18136, p18215, p19373, p18399 and p4741 gave transformants in B. linens ATCC 19391c, whereas none was obtained with p18135 (Fig. 1). The efficiency of transformation was identical for all these plasmids, localizing the minimal replicon within the $2.5 \mathrm{~kb}$ EcoRI-Pst I fragment borne by p18399. When these plasmids were isolated from $B$. linens ATCC 19391c and analysed by restriction mapping, no alteration in either their size or structure 


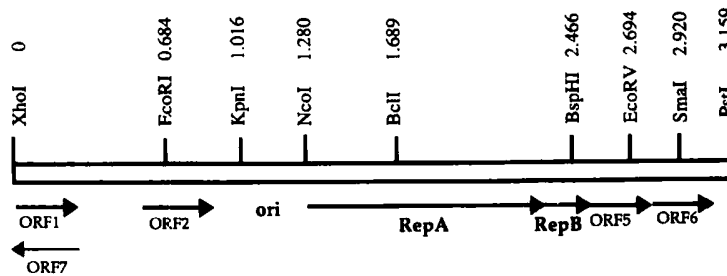

PA9394 (pBK/K-P)

PA9304 (pBK/K-S)

PA9400 (PBK/K-S)

pA7727 (pJRD16905/K-N)

pB2900 (pBK/K-N)

PB2932 (pJRD16905/K-N)
Replication in ATCC19391c containing :

no plasmid $\quad$ p4741

$+\quad+$

$+$

$+$

- +

- $\quad+$

Fig. 2. Genetic organization of the Xhol-Pst| fragment sustaining autonomous replication. The localization of ORFs in the Xhol-Pstl fragment is indicated. PBLA8 derivatives resulted from insertion of the indicated fragment into the vector, between the restriction sites specified in parentheses. The derivatives were selected in $E$. coli. Their replication ability $(+)$ or inability $(-)$ was analysed in B. linens ATCC 19391C in the presence or absence of $p 4741\left(\mathrm{Cm}^{R}\right)$, by selection of $\operatorname{Kan}^{R}$ or $\operatorname{Kan}^{R} \mathrm{Cm}^{R}$ transformants, respectively. In all cases resident and incoming plasmids were present simultaneously within the cell. S, Smal; N, Ncol; others as in Fig. 1. was observed when compared with the corresponding plasmid purified from E. coli. The copy number of pBLA8 and its replicative derivatives was estimated to be 30 per chromosome equivalent, suggesting that copy number control was not affected in any derivative.

\section{DNA sequence}

The complete nucleotide sequence of the $3159 \mathrm{bp}$ $X$ hoI-PstI fragment was determined. The $\mathrm{G}+\mathrm{C}$ content of this region, $62 \mathrm{~mol} \%$, is in agreement with the $\mathrm{G}+\mathrm{C}$ content of the $B$. linens chromosome $(60-64 \mathrm{~mol} \%)$ (Jones \& Keddie, 1986). The $\mathrm{G}+\mathrm{C}$ content is higher than that of C. glutamicum plasmids pSRI $(57 \mathrm{~mol} \%)$, pBL1 $(53 \mathrm{~mol} \%$ ) and pGA1 (54 mol \%) (Archer \& Sinskey, 1993; Filpula et al., 1986; Nesvera et al., 1997) and that of the $B$. linens plasmid pRBL1 $(60 \cdot 8 \mathrm{~mol} \%)$ (Ankri et al., 1996). Computer analysis revealed six complete ORFs oriented from left to right, and a partial one, ORF7, oriented from right to left and overlapping the $5^{\prime}$ end of the sequenced fragment (Table 1). All these ORFs possess a putative ribosome-binding site. The start codons of ORFs 4-6 overlaps the coding region of the preceding ORF, suggesting that they are part of the same operon. Various direct and indirect repeats are located within the sequence of the minimal replicon, suggesting that they could be involved in plasmid replication.

\section{Definition of ORFs and DNA sequences required for replication}

The EcoRI-PstI minimal replicon (p18399, Fig. 1) bears neither ORF1 nor ORF7 and contains only the $3^{\prime}$ end of ORF2. Hence, these three ORFs are dispensable for autonomous replication. This assumption was confirmed by the observation that it was possible to obtain transformants in B. linens ATCC 19391c with pA9394 carrying the KpnI-PstI fragment (Fig. 2). To analyse the requirement of the other ORFs for replication, we took advantage of unique restriction sites located within the region to construct deletion derivatives. ORF6 was deleted of its $3^{\prime}$ half in pA9304 (bearing the KpnI-SmaI fragment) and was completely deleted in pA9400 (bear- ing the KpnI-EcoRV fragment), the deletion extending into ORF5 (Fig. 2). Both plasmids replicate in ATCC 19391c; thus ORF5 and ORF6 are also dispensable for autonomous replication.

Further deletions towards the $K p n I$ site abolished autonomous replication. Thus, pA7727, carrying only the $5^{\prime}$ end of ORF4, and pB2900, deleted of ORF4 and of part of ORF3, was not replicative in ATCC 19391c. Considering the absolute requirement of ORF4 for autonomous replication, the requirement of ORF 3 could not be addressed with pB2900 since, whether ORF3 is functional or not, this plasmid does not show autonomous replication. Therefore, a frameshift mutation was created within ORF3. Plasmid pA9400 was cleaved at its unique $B c l$ I site and the ends were filled in with Klenow polymerase prior to ligation. The resulting plasmid did not give transformants in ATCC 19391c. Thus ORF3 is also necessary for autonomous plasmid replication.

All these $\mathrm{Km}^{\mathrm{R}}$ pBLA8 derivatives, including $\mathrm{pB} 2932$ (Fig. 2), gave $\mathrm{Kan}^{\mathrm{R}} \mathrm{Cm}^{\mathrm{R}}$ transformants when they were introduced into ATCC $19391 \mathrm{c}$ containing $\mathrm{p} 4741\left(\mathrm{Cm}^{\mathrm{R}}\right.$, bearing the $\mathrm{XhoI}-\mathrm{Pst} \mathrm{I}$ fragment; see Fig. 1 ). The analysis of their restriction maps revealed that they all carried the KpnI-Ncol fragment, which does not contain any ORFs, but permits the replication of pB2932 in trans of p4741. The analysis of the transformant plasmid content showed that pB2932 and p4741 were both present. The KpnI-NcoI region must carry DNA signals able to promote replication in the presence of diffusible factors provided by $\mathrm{p} 4741$, and therefore corresponds to an ori site.

In summary, the minimal region required for replication could be reduced to a $K p n \mathrm{I}-E c o \mathrm{RV}$ fragment that contains an ori site and two ORFs, ORF3 and ORF4, that have been named rep $A$ and rep $B$ respectively.

\section{ORF7 is homologous to KfrA}

Only the first 172 residues of ORF7 are encoded by the $X h o l$ end of the XhoI-PstI sequence. This polypeptide is similar to the KfrA protein of plasmid RK2 (Thomas 
KfrA

MELNKE--TRDRIFAMADELFEQGDRENFPTVDAVRKAARVNMNDASAGMREWRRQRTAQAAPLAVQVPD 68

ORF 3 PBLA8 MTDDQSPETRA-- EAMARDLADTGRAV--TARAIREAAKVRMAVAMATAKAMNDAASEDDHETIPAVPE 65

Kf $\mathrm{AA}$ AVQQAGNQAVAALWQMAQALANESLQAAQAGWDRERNELEAVRGELADAFEAQARELEEAQARVTLLEQQ 138 ORF 3 PBLA8 DVTGALTAIWADAYRAALAVTPERDQLRSDVDALRVEV -..-QLTADV-ETVEAIRDTATTQADTLRKE 130

KFYA ANMAELAARQRQALAEARTALAGAEQRAALATQRADEVERRAQELRAELDYAHQDARAFKEESRKTLDA 207 ORF3 PBLA8 LANAKAEAEKWSTEANKHEAALSAVRDQHDKLNERITTLLLA
Fig. 3. Alignment of pBLA8 ORF7 with the KfrA protein of plasmid RK2. Identical amino acid residues are shown in bold type; conservative substitutions are marked with asterisks.

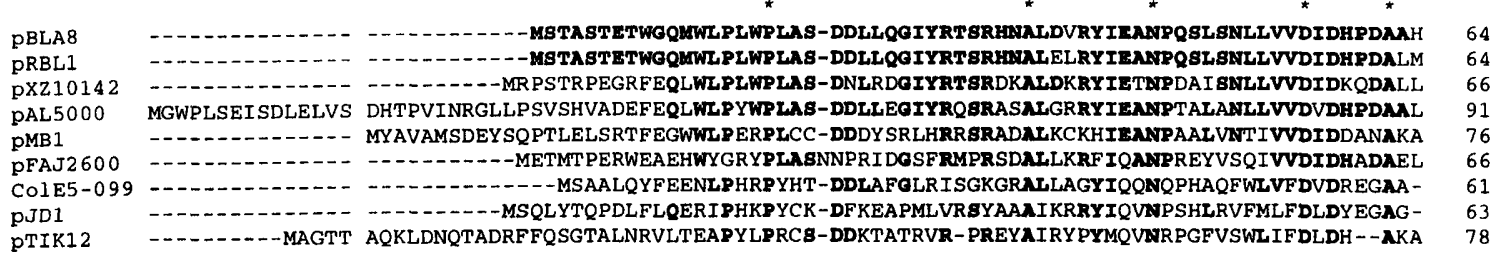

bhhhhigrohohh h

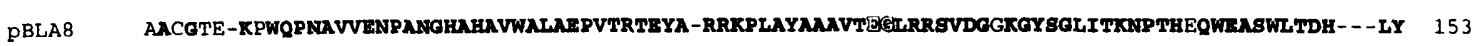
PRBL1 RAMWNR-KAWQPNAVVENPANOHAEAVWALAEPVTRTEYA-RRKPLAYNANVTEGLRREVDGDKCYSCLITKAPTHDQWEASWLTDH---LY 153 pXZ10142 RSMWDR-DGWRPNAVVENPXNOHAHAVWALAEPVTRTEYA-RRKPXAYMANVTEGLRRGVDODKOYBOLITKWPEHTAWDSHWVTDK---LX 155 PAL5000 RALSARGSHPLPNAIVGNRAMOHAHAVWALNAPVPRTEYA-RRKPLAYMAACAEGLRRAVDGDRSYBGLMTKMPGHIAWETEWLHSD- - -LY 181 PMB1 MALWEH-EGMRPAWIAENPANGHAHAGWVTFPVPRTDLA-RLKPLKLLHATTEGLRRECDODMOYSGLLMGMPEHPAWASDI IEWD---TY 165 PFAJ 2600 RAFSMHEVGLVPNMFAYSTRPGHGQATFLLRSPVSLSEAS-RRKPINLLARCQQGLTVALSGDPHYSGPLARMPTHPMANTRWCHPT - - PY 156 CO1E5-099 IDWSDR-NAPAPNITVKNPVNGWAHLLYALNIAVRTAPDA-SVKALKYANAI ERALCEKLGADVNY8CLICKWPFHLEWLVMEWREE---AY 150 pJD1 LAWEDN-NLPMPAWAA INREWGGAHLAYALSAPVLTAEYGGRQKALRYLAALEAAYKAKLRGDVGFVSLITKWPEHPHWLTLRGVPDAIRGY 156 PTIK12 MIWEDA-GLPAPNLIVRNRQSGHSHLYYAIP-PVCTTETA-RSKPIAYMKTVYGCLD-_-_-_-FHSOPVAKTPGHPWWLTHELHAH---VY 159

\begin{tabular}{|c|c|c|c|c|}
\hline pBLA8 & NLDELTEHLTVSDFUPRDSWQRTKRKINPVGLORWCTLFETT & & & 238 \\
\hline pRBL1 & NLDELTEHLYVSDFUPPDSWQRTKRKNPVGLORWCTLFETVRWDV & VARTIRKRNEHPT PIDREDLEAAIVNLCQGMNSTF & $\mathbf{L}$ & 239 \\
\hline $\mathrm{pXz10142}$ & TLDELRFWLEETGFMP PESWKKTRRKSP IOLGRNCALERSARSWA & EIRHHFG - - - - DPDGLGRS IQATAQALNQILL-- & PLL & 234 \\
\hline pAL 5000 & TLSHIEAELGANMP PPRWRQQTTYKAAPTPLGRNCALFDSVRLWA & PALMR - - - IYLPTRNVDGLGRAIYAECHARNAFFPCNDV & GPL & 267 \\
\hline pMB1 & DLEQLVQSLQEHGDMPPVSWKRTKRARTQGLORNCTLFDKARTLA & YVAAAAD---R-SEASSEALRLYVRRTCHELNVSL---- & PDPL & 247 \\
\hline PFAJ 2600 & ELRDLARALGRDLPWPP-TSRRVEAS IDSALGRNCWMFDVTRQV & AWTRYP-1-----QRTDWDDAVFAYTWGRNPELVS & KGPL & 236 \\
\hline ColE5-099 & TLDELADYLDLSASARR------SIDKHYGMGRWCHLFIMTRKWAYE & 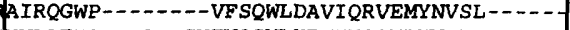 & PVPL & 222 \\
\hline pJD1 & DLEYLADFVDLDKFKPYIG-R--SNVEAVOLSRNCTVFNLVSRWAH & WVLAF KQ - - -Q--GYTVQGWLKEVHYQCMRVNGDF--- & PVPM & 236 \\
\hline pTIK12 & ELGEIADYVDLAVSSPWGKG---PQFDEVSHSRHCILFEHLRDYAYS & IVNRERE - - - - - RGSFGTFTRVLEAYAHNRNSFQKLG-- & MDNL & 239 \\
\hline
\end{tabular}

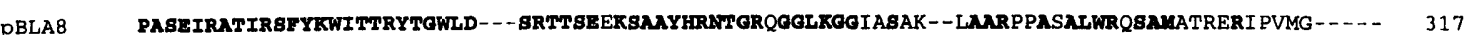

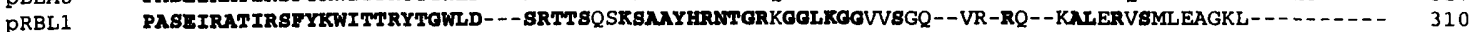
PXZ10142 PVAEVDOIARSIHRWI ITKSRMWTD---GPAVYEATFTTIQATRGKRS-_-

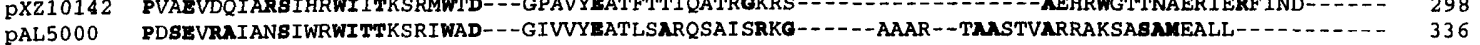
PMB1 HAREVEDIAKSI HKWIVTRSRMWRD-- -GAIANAATFIAIQSARGHKHG- 1 PFAJ2600 PDSELRTISRSVASFVWN-SEMRAK---GAEQFDADFSKIQANRGHKGO---KTMTEK--RREVIAETNRRRKVDRAAVLAELEA------ 310 COIE5-099 SPAECRAIGKSIAKYTHRNFTPETF---AQYVADTHTPEIQAARGRKOGKIOGAKBKRGAVATSARTLKPWETLGISRAWYYQLKKRGLVE 308 DJD1 WEKEVKCISKGIANWVWYKFDIAAS- - NRRFGELQ-_-AHRNSLRKT_-

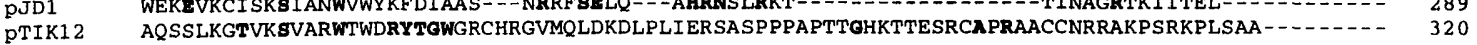

Fig. 4. Alignment of the PBLA8 RepA deduced amino acid sequence with homologous Rep proteins. ColE5-099 Rep is representative of the ColE2-related plasmid family. Two positions with presumptive frameshifts in pXZ10142 RepA sequence are translated as an X, as previously proposed (De Mot et al., 1997). Bold characters indicate the residues of RepA from pBLA8 that are conserved in the other proteins. Positions with identical residues in all the sequences are indicated $(*)$. The consensus motif of primases is shown above the alignment. The boxed sequence indicates the nonconserved region.

et al., 1995) (Fig. 3). KfrA is a protein of 308 residues (Thomas et al., 1995) and is almost entirely $\alpha$-helical (Jagura-Burdzy \& Thomas, 1992). This property was also predicted for the truncated ORF7. The typical extended coiled-coil domain of $\mathrm{KfrA}$, containing a heptad repeat segment, is located outside the sequenced region of ORF7. The region containing the helix-turnhelix (HTH) domain of $\mathrm{KfrA}$ is poorly conserved in ORF7, and such a motif was not predicted. KfrA was reported to be involved in plasmid partitioning; nevertheless its inactivation did not significantly alter the plasmid copy number. The same observation could be made for pBLA8 ORF7, since it is destroyed in several pBLA8 derivatives that proved to be as stable as the native plasmid. Hence, if present on $\mathrm{pBLA} 8$, partition functions encoded by ORF7 are not crucially important for the maintenance and heredity of this high-copynumber plasmid. 


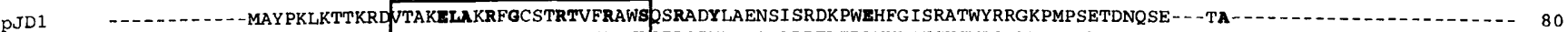

PAL 5000 MSDGY SDGYSDGYNRQPTVRKKRR VTAAIEARI TGLSERHVVRLVAQERSEWLAEQAARRERIRAYHDDEGHSWPQTAKHFOLHLDTVKRLGYRARKERAAEOEAAQKAHNEADNP PLF - 119

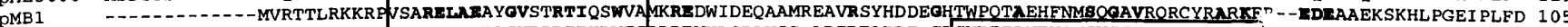

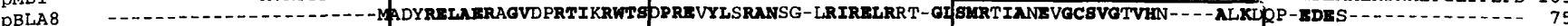

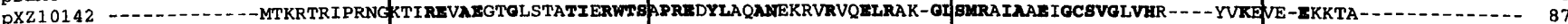
PFAJ 2600 - -

HTH 1

HTH 2

Fig. 5. Sequence alignment of RepB from pBLA8. The RepB putative protein sequence was aligned with homologues from plasmids pAL5000, pMB1, pXZ10142, pFAJ2600 and pJD1. Bold characters indicate the residues of RepB from pBLA8 that are conserved in the other proteins. The HTH motifs (1 and 2), predicted by the method of Dodd \& Egan (1990), are boxed.

\section{RepA is homologous to replication proteins associated with theta replication}

A search of the GenBank protein database revealed that RepA is related to Rep proteins of various plasmids. The best scores corresponded to the Rep protein of $\mathrm{pRBL} 1$ (from B. linens) (Ankri et al., 1996), RepA of pAL5000 (Mycobacterium fortuitum) (Stolt \& Stoker, 1996), RepA of pMB1 (Bifidobacterium longum) (Rossi et al., 1996), RepA of pJD1 (Neisseria gonorrboeae) (Korch et al., 1985), Rep of pTiK12 (Thiobacillus intermedius) (English et al., 1995) RepA of pXZ10142 (C. glutamicum) (accession no. X726910), RepA of pFAJ2600 of Rhodococcus erythropolis (De Mot et al., 1997) and the Rep proteins of ColE2-related plasmids: ColE2-GEI602, ColE2-CA42, ColE6-CT14, ColE7K317, ColE4-CT9, ColE5-099, ColE9-J, ColE2immK317, ColE3-CA38, ColE8-J and ColE2-P9 (Hiraga et al., 1994). These protein sequences were aligned using the CLUSTAL w program. As the Rep proteins encoded by ColE2-related plasmids vary by a few residues only, we used ColE5-099 as the representative in the plasmid comparisons shown in Fig. 4.

We did not observe any homology with the Rep proteins of other plasmids, notably the rolling-circle-replication Rep proteins. Moreover, no DNA motif characteristic of these plasmids was identified. Since the rolling-circlereplication plasmids characterized so far are highly interrelated, as shown by Gruss \& Ehrlich (1989), pBLA8 presumably does not use this mode of replication. pBLA8 does not share significant homology with C. glutamicum plasmids pBL1, pSR1, pNG2 or pGA1. The Rep proteins of pSR1, pNG2 and pGA1, which replicate via the rolling-circle mechanism, are related, but show no significant homology with that of pBLA8. pBLA8, pRBL1 and pXZ10142 constitute a new family of theta-replicating plasmid's in corynebacteria.

\section{RepB is homologous to other RepB proteins}

RepB is required for plasmid replication. Database searches revealed significant homology with RepB proteins encoded by pJD1, pAL5000, pMB1, pXZ10142 and pFAJ2600. The most highly conserved region is located at the $\mathrm{N}$ terminus of these proteins. Using the method of Dodd \& Egan (1990), an HTH motif (HTH 1, Fig. 5) was predicted in this region. De Mot et al. (1997) described a second HTH motif (HTH 2, Fig. 5) at the C-terminus of the proteins encoded by pXZ10142 and pFAJ2600; this motif is also present in the pBLA8 RepB protein.

In pBLA8, as in pAL5000, pMB1, pXZ10142, pJD1 and $\mathrm{pFAJ} 2600, \operatorname{rep} B$ is located downstream of, and overlaps, $r e p A$, suggesting that they are both part of the same operon. The RepB protein of pAL5000 was shown to bind to DNA near the ori site (Stolt \& Stoker, 1996). Considering the presence of an HTH motif and the homology with pAL5000, we could speculate that the other RepB proteins have the same function. Available sequence data concerning pRBI 1 cover only $\operatorname{rep} A$, but nevertheless the minimal regio 1 necessary for autonomous replication is larger than repA (Ankri et al., 1996). So, considering the high homology with pBLA8, the existence of a $\operatorname{rep} B$ gene in this region is highly probable. pTIK12 has a single Rep protein (English et al., 1995). It is noteworthy that this Rep protein is also the most distant from pBLA8 RepA and is very close to ColE2 Rep.

\section{The ori region}

When comparing the pBLA8 region containing the ori site with the DNA sequence of related plasmids, the conserved motif TCAGAT was found in all the plasmids except for pFAJ2600, where only a TC--AT motif was present at the same position (Fig. 6). This motif is located upstream of $r e p A$ and '; complementary to the ppApGpA initiator RNA, found in the ori region of ColE2 plasmids (Hiraga et $: i, 1,4)$. It is positioned close to the RepB-binding ss: $i_{1}$ rAL5000 (Stolt \& Stoker, 1996). So, considerit, in nomology with the ColE2 initiation site, it couis the speculated that the replication fork is initiated a: this site and moves unidirectionally in the oppositc direction to rep gene transcription.

\section{pBLA8 belongs to a Gram-positive subfamily of ColE2-related plasmids}

The results of the RepA sequence alignment (Fig. 4) clearly show that all the Rep proteins analysed are homologous and several amino acids are conserved in all of them. Thus they belong to the theta replicases of the ColE2 family. The existence of additional conserved motifs among the RepA proteins of pBLA8, pRBL1, pXZ10142, pAL5000 and pMB1 suggests that these 
distance from

RepA start codon

$\begin{array}{lrl}\text { pBLA8 } & -68 & \text { GAAAGCAATATCAGATGGTTCCGGC } \\ \text { pRBL1 } & -68 & \text { GAAAGCAATATCAGATGGTTCCTGC } \\ \text { pMB1 } & -26 & \text { GGGAACCAAGTCAGATATTTCAGCC } \\ \text { pXZ10142 } & -65 & \text { CGTAACCAAGTCAGATGTTTCCGGG } \\ \text { pAL5000 } & -45 & \text { GAGCTCCAAGTCAGATATTTCGCTG } \\ \text { pJD1 } & -106 & \text { ATAACCATAATCAGATAACAGCCCG } \\ \text { pFAJ } 2600 & -89 & \text { AGTCAGGTAGTCGAATTTTHGGAGC } \\ \text { ColE2 } & & \text { ATAAGCCTTATCAGATAACAGCGCC }\end{array}$

Fig. 6. Alignment of the putative ori site of PBLA8, PRBL1, pMB1, pXZ10142, pFAJ2600, plL5000 and pJD1 with the ColE2 ori site. Except for ColE2, all the ori sequences analysed are located upstream of the rep operon and they work in the opposite direction to rep transcription. The distance of their $5^{\prime}$ end from the Rep translation initiation codon is indicated. Bold characters indicate pBLA8 nucleotides that are highly conserved in the other sequences. The primer RNA (5'ppApGpA) for leading strand synthesis (arrow) for ColE2 plasmids is indicated $(\star \star \star)$.

proteins may constitute a Gram-positive Rep subfamily of ColE2-related plasmids. This family would be characterized by proteins containing two conserved regions spaced by a poorly related region, in contrast to the Rep proteins of other ColE2-related plasmids, which are highly homologous throughout their sequences except in the last 30 residues (Hiraga et al., 1994). The $\mathrm{N}$ terminal region is the most highly conserved domain and, furthermore, it contains most of the motifs shared with the Rep proteins of ColE2-related plasmids. This region is involved in primase activity (Hiraga et al., 1994). Moreover, the amino acid sequence motif described for bacterial primases (Pansegreau \& Lanka, 1992 ) is present in all members of the pBLA8 RepA subfamily. The spacer region is weakly conserved in pBLA8 and pRBL1 Rep proteins, not at all in the Rep proteins originating from other Gram-positive bacteria, and is clearly divergent from the Rep proteins of ColE2related plasmids. The C-terminal domain is poorly homologous among these proteins, except for pBLA8 and pRBL1, which share significant homology. It is also the most divergent region in the Rep proteins of ColE2related plasmids. It contains the HTH motif interacting with ori and responsible for ori binding specificity (Hiraga et al., 1994). Such a motif is lacking in RepA proteins of the pBLA8 subfamily.

The existence of this subfamily was confirmed at the DNA level. A c': tat ase search for DNA homologies among pBLA8 and DNA sequences, revealed strong homology throughout the sequence with pRBLI $(84 \%)$ but restricted to the sequence encoding the $\mathrm{N}$-terminal domain of the Rep protein from pXZ10142 $(72 \%)$, pAL5000 $(67 \%)$ and pMBI $(57 \%)$. This suggests an ancestral replication module common to all these plasmids that emerged after, or independently of, the highly conserved module in the ColE2 family. This REP module, common to all the proteins analysed, encoded primase activity. Each Rep DNA-binding site and ori site evolved simultaneously in each plasmid. Such a mosaic structure, and evolution by the exchange of functional parts of the replicon via homologous recombination, has been described for ColE2 derivatives (Hiraga et al., 1994). These replication functions originate from a common ancestor which invaded the eubacteria of different phyla and evolved divergently to optimize host/plasmid interactions.

The ColE2 Rep protein has two activities. First, it binds specifically to ori (Shinohara \& Itoh, 1996). Second, the protein is a site-specific primase, since it is able to synthesize a short RNA molecule from a supercoiled template (Takechi et al., 1995). In pBLA8-related plasmids, RepB proteins (DNA-binding) should act together with RepA (primase) to initiate DNA replication in a way similar to Rep of ColE2, which possesses both activities. In all these plasmids, RepA and RepB seem to be encoded by a single operon, $r e p A B$. Another structural feature of these plasmids is the location of the ori site upstream of $\operatorname{rep} A B$, the replication fork moving in the opposite direction to $\operatorname{rep} A B$ transcription. ori is located downstream of the rep gene in ColE2, the replication fork moving in the same direction as rep transcription. Considering the nucleotide sequence of the ori site (Fig. 6), we can distinguish two groups, the first including pRBL1, pBLA8, pMB1, pXZ10142 and pAL5000, the second including pJD1 and the ColE2 family. The ori site of pFAJ2600 is unique. This grouping is identical to that observed for RepA proteins and must have a functional significance. Thus, considering all these structural differences, it is clear that the ColE2 family is composed of two structural subfamilies, the first including ColE2 derivatives and probably pTIK12, and the second made up of pBLA8, pRBL1, pXZ10142, pAL5000, pMB1, pFAJ2600 and pJD1.

\section{pA2209: an E. coli-B. linens shuttle vector}

To construct an efficient shuttle vector, we used pBluescriptII SK + , considering its advantages for the direct selection of recombinant plasmids in E. coli. It was modified by adding pBLA8 replication functions and a phenotypic marker active in corynebacteria (Fig. 7).

The stability of pA2209 was analysed in ATCC 19391c. After 80 generations without antibiotic, only $2 \%$ of the cells had lost the plasmid. Hence it could be used for continuous-culture fermentation in the absence of any selective pressure. This stability was not modified by introducing an EcoRI fragment bearing a chloramphenicol-resistance determinant into the vector (data not shown).

\section{Host spectrum of pBLA8 derivatives}

When pA2209 was introduced by electroporation into other corynebacteria, no $\mathrm{Kan}^{\mathrm{R}}$ colonies were recovered with any of the C. glutamicum strains analysed, in- 


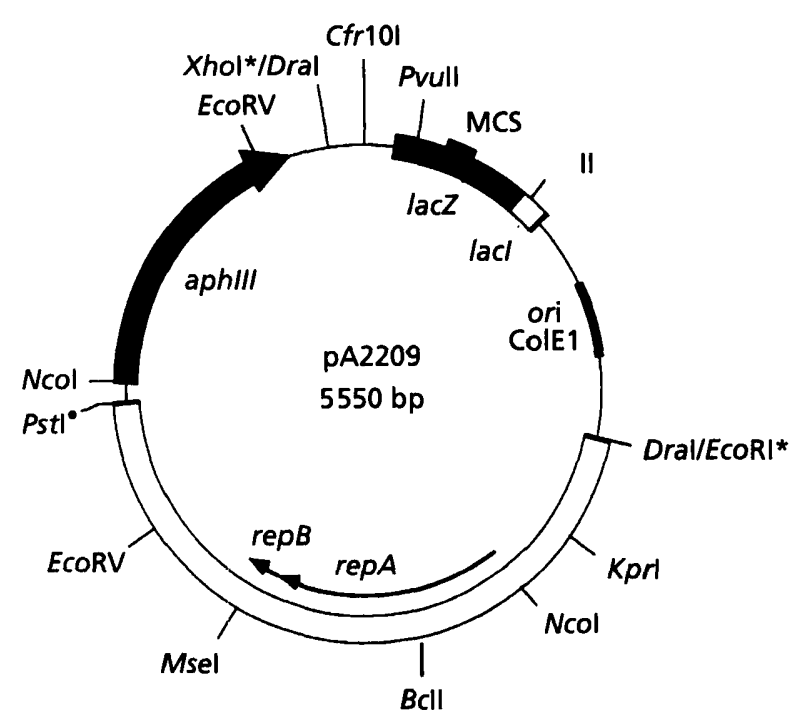

Fig. 7. E. coli-B. linens shuttle vector pA2209. *, Sites destroyed following Klenow polymerization; $O$, sites destroyed by S1 limited digestion. MCS (multiple-cloning site) contains (clockwise) Kpnl, Apal, Drall, Xhol, Hincll, Sall, Clal, Hindlll, EcoRV, EcoRI, Pstl, Smal, BamHI, Spel, Xbal, Notl, Sadl, Sacl. Bold restriction sites indicate unique sites.

cluding BLI5 and RM3, in spite of the fact that these restriction-defective strains were efficiently transformed with p21530 and p25450, the derivatives of pBL1 and pCG100 respectively. In contrast, $\mathrm{Kan}^{\mathrm{R}}$ colonies were obtained with Artbrobacter sp. SI55, 'A aureus' C70, A. globiformis and A. ramosus with a high efficiency $\left(10^{6}\right.$ transformants per $\mu \mathrm{g}$ DNA), identical to that obtained when p21530 and p25450 were transformed in C. glutamicum BLI5 and RM3. ' $A$. aureus' C70 had been previously shown to have no restriction activity against E. coli DNA (Le Marrec et al., 1994). Arthrobacter sp. SI55 and A. globiformis show the same behaviour. The host spectrum did not include all Arthrobacter strains, since A. simplex and A. variabilis could not be transformed by pBLA8 derivatives. This discrepancy in the Arthrobacter strain behaviour should perhaps be considered in the context of the heterogeneity of this genus. Thus, the cell wall of $A$. variabilis, containing meso-diaminopimelate and mycolic acids, indicates that it is closely related to the genus Corynebacterium (Keddie et al., 1986). Likewise A. simplex is also phenotypically and genomically distinct from Arthrobacter sensu stricto, and it has been proposed that this bacterium should also be reclassified (Keddie et al., 1986).

The stability of pA2209 was assayed in these strains. In each case, only $3 \%$ of the cells lost the plasmid after 80 generations in the absence of selective pressure. In spite of the fact that pBLA8 and pRBL1 are highly homologous and originate from $B$. linens, they have different host spectra. Thus only pRBL1 derivatives are able to replicate in C. glutamicum (Ankri et al., 1996). pBL33 and $\mathrm{pBL} 100$ have a restriction map identical to that of pBLA8, yet pBL33 was shown to replicate in Rhodococcus sp. R312 (formerly Brevibacterium sp. R312) (Bigey et al., 1995). Since other bacteria have not yet been tested, it is difficult to compare the host spectrum of pA2209 with that of pBL33.

Compatibility of the pBLA8 derivative $\mathrm{p} 4741\left(\mathrm{Cm}^{\mathrm{R}}\right)$ with p21530 (pBL1 replicon, $\mathrm{Km}^{\mathrm{R}}$ ) and p25450 / $\mathrm{pCG} 100$ replicon, $\mathrm{Km}^{\mathbf{R}}$ ) was investigated in ' $A$. aurev' $:$ '. Both pairs of plasmids were maintained in the presence of kanamycin and chloramphenicol. In the absence of selective pressure, $\mathrm{p} 25450$ and $\mathrm{p} 4741$ were both found to be present after 80 generations. Because of the intrinsically high instability of p21530 (it is lost after 10 generations), the strain containing p21530 and p4741 contains only p4741 after 10 generations in the absence of antibiotic. In the presence of kanamycin, both plasmids were present after 80 generations. Thus pBLA8 is compatible with pBL1 and pCG100. The compatibility of $\mathrm{pBL} 1$ derivatives and $\mathrm{pBL} 100$ has also been described by Sandoval et al. (1985).

\section{ACKNOWLEDGEMENTS}

We are grateful to Laurent Jannière for helpful advice and critical reading of the manuscript.

This work was supported by the Direction de la Recherche et des Etudes Doctorales and The Centre National de la Recherche Scientifique.

\section{REFERENCES}

Altschul, S. F., Gish, W., Miller, W., Myers, E. W. \& Lipman, D. J. (1990). Basic local alignment search tool. J Mol Biol 215, 403-410.

Ankri, S., Bouvier, I., Reyes, O., Predali, F. \& Leb ,n, G. (1996). A Brevibacterium linens $\mathrm{pRBL} 1$ replicon functic al in Corynebacterium glutamicum. Plasmid 36, 36-41.

Archer, J. A. C. \& Sinskey, A. J. (1993). The DNA sequence and minimal replicon of the Corynebacterium glutamicum plasmid pSR 1: evidence of a common ancestry with plasmids from $C$. diphtheriae. J Gen Microbiol 139, 1753-1759.

Bardonnet, N. \& Blanco, C. (1991). Improved vectors for transcriptional signal screening in corynebacteria. FEMS Microbiol Lett 84, 97-102.

Bartolomé, B., Jubete, Y., Martinez, E. \& de la Cruz, F. (1991). Construction and properties of a family of pACYC184-derived cloning vectors compatible with $\mathrm{pBR} 322$ and its derivatives. Gene $102,75-78$.

Bigey, F., Grossiord, B., Chan Kwo Chion, C. K., Arnaud, A. \& Galzy, P. (1995). Brevibacterium linens pBL33 and Rhodococcus rhodochrous pRC1 cryptic plasmids replicate in $R$ bodococcus $\mathrm{sp}$. R312 (formerly Brevibacterium sp. R312). Gene 154, 77-79.

Bonnassie, S., Oreglia, J., Trautwetter, A. \& Sicard, A. M. (1990). Isolation and characterization of a restriction and modification deficient mutant of Brevibacterium lactofermentum. FEMS Microbiol Lett 72, 143-146.

Collins, M. D. \& Cummins, S. C. (1986). Genus Corynebacterium. In Bergey's Manual of Systematic Bacteriology, p. 1266. Edited by J. G. Holt. Baltimore: Williams \& Wilkins.

Correia, A., Martin, J. F. \& Castro, M. (1994). Pulsed-field gel 
electrophoresis analysis of the genome of amino acid producing corynebacteria: chromosome sizes and diversity of restriction patterns. Microbiology 140, 2841-2847.

De Mot, R., Nagy, I., De Schrijver, A., Pattanapipitpaisa, P., Schoofs, G. \& Vanderleyden, J. (1997). Structural analysis of the $6 \mathrm{~kb}$ cryptic plasmid pFAJ2600 from Rhodococcus erythropolis NI86/21 and construction of Escherichia coli-Rhodococcus shuttle vectors. Microbiology 143, 3137-3147.

Dodd, I. B. \& Egan, J. B. (1990). Improved detection of helix-turnhelix DNA-binding motifs in protein sequences. Nucleic Acids Res 18, 5019-5026.

English, R. S., Lorbach, S. C., Huffman, K. M. \& Shively, J. M. (1995). Isolation and characterization of the replicon of a Thiobacillus intermedius plasmid. Plasmid 33, 1-6.

Fernandez-Gonzalez, C., Cadenas, R. F., Noirot-Gros, M. F., Martin, J. F. \& Gil, J. A. (1994). Characterization of a region of plasmid pBL1 of Brevibacterium lactofermentum involved in replication via the rolling circle model. J Bacteriol 176, 3154-3161.

Filpula, D., Ally, A. H. \& Nagle, J. (1986). Complete nucleotide sequence of a native plasmid of Brevibacterium lactofermentum. Nucleic Acids Res 14, 5114.

Gruss, A. \& Ehrlich, S. D. (1989). The family of highly interrelated single-stranded deoxyribonucleic acid plasmids. Microbiol Rev 53, 231-241

Hiraga, S.-I., Sugiyama, T. \& Itoh, T. (1994). Comparative analysis of the replicon regions of eleven ColE2-related plasmids. $J$ Bacteriol 176, 7233-7243.

Jagura-Burdzy, G. \& Thomas, C. M. (1992). kfrA gene of broad host range plasmid RK2 encodes a novel DNA-binding protein. $J$ Mol Biol 225, 651-660.

Jones, D. \& Keddie, R. M. (1986). Genus Brevibacterium. In Bergey's Manual of Systematic Bacteriology, p. 1301. Edited by J. G. Holt. Baltimore: Williams \& Wilkins.

Kato, F., Hara, N., Matsuyama, K., Hattori, K., Ishii, M. \& Murata, A. (1989). Isolation of plasmids from Brevibacterium. Agric Biol Chem 53, 879-881.

Keddie, R. M., Collins, M. D. \& Jones, D. (1986). Genus Arthrobacter. In Bergey's Manual of Systematic Bacteriology, p. 1288. Edited by J. G. Holt. Baltimore: Williams \& Wilkins.

Korch, C., Hagblom, P., Ohman, H. M. G. \& Normark, S. (1985). Cryptic plasmid of Neisseria gonorrboeae: complete nucleotide sequence and genetic organization. J Bacteriol 163, 430-438.

Le Marrec, C., Michotey, V., Blanco, C. \& Trautwetter, A. (1994). $\phi$ AAU2, a temperate bacteriophage specific for 'Arthrobacter aureus', whose integrative functions work in other corynebacteria. Microbiology 140, 3071-3077.

Le Marrec, C., Moreau, S., Loury, S., Blanco, C. \& Trautwetter, A. (1996). Genetic characterization of site-specific functions of $\phi$ AAU2 infecting 'Arthrobacter aureus' C70. J Bacteriol 178, 1996-2004.

Mandel, M. \& Higa, A. (1970). Calcium-dependent bacteriophage DNA infection. J Mol Biol 53, 159-162.

Martin, J. F., Santamaria, R., Sandoval, H., Del Real, G., Mateos, L. M., Gil, J. A. \& Aguilar, A. (1987). Cloning systems in amino acid-producing corynebacteria. Bio/Technology 5, 137-146.

Mead, D. A., Skorupa, E. S. \& Kemper, B. (1985). Single stranded DNA SP6 promoter plasmid for engineering mutant RNAs and proteins: synthesis of a 'stretched' preproparathyroid hormone. Nucleic Acids Res 13, 1103-1118.

Miller, J. H. (1972). Experiments in Molecular Genetics. Cold Spring Harbor: Cold Spring Harbor Laboratory.
Moreau, S., Leret, V., Le Marrec, C., Varangot, H., Ayache, M., Bonnassie, S., Blanco, C. \& Trautwetter, A. (1995). Prophage distribution in coryneform bacteria. Res Microbiol 146, 493-505.

Nesvera, J., Patek, M., Hochmannova, J., Abrhamova, Z., Becvarova, V., Jelinkova, M. \& Vohradsky, J. (1997). Plasmid pGA1 from Corynebacterium glutamicum codes for a gene product that positively influences plasmid copy number. J Bacteriol 179, 1525-1532.

Pansegreau, W. \& Lanka, E. (1992). A common sequence motif among prokaryotic DNA primases. Nucleic Acids Res 20, 4931.

Pearson, W. R. \& Lipman, D. J. (1988). Improved tools for biological sequence comparison. Proc Natl Acad Sci USA 85, 2444-2448.

Rossi, M., Brigidi, P., Gonzalez Vara y Rodriguez, A. \& Matteuzzi, D. (1996). Characterization of the plasmid pMB1 from Bifidobacterium longum and its use for shuttle vector construction. Res Microbiol 147, 133-143.

Sambrook, J., Fritsch, E. F. \& Maniatis، T. (1989). Molecular Cloning : a Laboratory Manual, 2nd edn. Cold Spring Harbor: Cold Spring Harbor Laboratory.

Sandoval, H., Del Real, G., Mateos, L. M., Aguilar, A. \& Martin, J. F. (1985). Screening of plasmids in non-pathogenic corynebacteria. FEMS Microbiol Lett 27, 93-98.

Sanger, F., Nicklen, S. \& Coulson, A. R. (1977). DNA sequencing with chain-terminating inhibitors. Proc Natl Acad Sci USA 74, 5463-5467.

Santamaria, R., Gil, J. A., Mesas, J. M. \& Martin, J. F. (1984). Characterization of an endogenous plasmid and development of cloning vectors and a transformation system in Brevibacterium lactofermentum. J Gen Microbiol 130, 2237-2246.

Schafer, A., Kalinowski, J., Simon, R., Seep-feldhaus, A.-H. \& Puhler, A. (1990). High-frequency conjugal plasmid transfer from gram-negative Escherichia coli to various gram-positive coryneform bacteria. J Bacteriol 172, 1663-1666.

Serwold-Davis, T. M., Groman, N. B. \& Kao, C. C. (1990). Localization of an origin of replication in Corynebacterium diphtheriae broad host range plasmid pNG2 that also functions in Escherichia coli. FEMS Microbiol Lett 66, 119-124.

Shinohara, M. \& Itoh, T. (1996). Specific determinants in interaction of the initiator (Rep) proteins with the origins in plasmids ColE2-P9 and ColE3-CA38 identified by chimera analysis. J Mol Biol 257, 290-300.

Spratt, B. G., Hedge, P. J., Te Heesen, S., Edelman, A. \& BroomeSmith, J. K. (1986). Kanamycin-resistant vectors that are analogues of plasmids pUC8, pUC9, pEMBL8 and pEMBL9. Gene 41, 337-342.

Stolt, P. \& Stoker, N. G. (1996). Functional definition of regions necessary for replication and incompatibility in the Mycobacterium fortuitum plasmid pAL5000. Microbiology 142, 2795-2802.

Takechi, S., Matsui, H. \& Itoh, T. (1995). Primer RNA synthesis by plasmid-specified Rep protein for initiation of ColE2 DNA replication. EMBO J 14, 5141-5147.

Thomas, C. M., Smith, C. A., Ibbotson, J. P., Johnston, L. \& Wang, N. (1995). Evolution of the korA-oriV segment of promiscuous IncP plasmids. Microbiology 141, 1201-1210.

Thompson, J. D., Higgins, D. G. \& Gibson, T. J. (1994). Clustal w : improving the sensitivity of progressive multiple sequence alignment through sequence weighting, position-specific gap penalities and weight matrix choice. Nucleic Acids Res 22, $4673-4680$.

Trautwetter, A. \& Blanco, C. (1988). Isolation and preliminary 
characterization of twenty bacteriophages infecting either Brevibacterium or Arthrobacter strains. Appl Environ Microbiol 54, 1466-1471.

Trautwetter, A. \& Blanco, C. (1991). Structural organization of the Corynebacterium glutamicum plasmid pCG100. J Gen Microbiol 137, 2093-2101.
Zhang, Y., Praszkier, J., Hodgson, A. \& Pittard, A. J. (1994). Molecular analysis and characterization of a broad-host-range plasmid, pEP2. J Bacteriol 176, 5718-5728.

Received 6 March 1998; revised 15 June 1998; accepted 23 June 1998. 